Infotek : Jurnal Informatika dan Teknologi

Vol. 3 No. 2, Juli 2020, hal. 211-219

\title{
Media Pembelajaran Interaktif Pengenalan Huruf Berbasis Flash Pada Siswa Pendidikan Anak Usia Dini (PAUD) (Studi Kasus : Kelompok Belajar Tarbiyatul Ummah Tanak Kaken Sakra Barat)
}

\author{
Fathurrahman'1, Yupi Kuspandi Putra2, Muhamad Sadali ${ }^{3}$ \\ 1,2Program Studi Sistem Informasi, Universitas Hamzanwadi \\ 3Program Studi Teknik Informatika, Universitas Hamzanwadi \\ fathurrahman.bloger@gmail.com
}

\begin{abstract}
Abstrak
Tujuan penelitian ini adalah untuk mempermudah guru dalam penyampaian materi kepada siswa dan meningkatkan pemahaman siswa terhadap materi yang disampaikan serta sebagai media untuk meningkatkan minat belajar dan kesenangan dalam proses belajar. Media pembelajaran memiliki peran penting dalam proses belajar mengajar, namun kenyataan didunia pendidikan media pembelajaran sering diabaikan dengan alasan terbatasnya waktu untuk membuat persiapan mengajar dan sulit mencari media yang tepat. Di Kelompok Belajar Tarbiyatul Ummah Tanak Kaken menggunakan media pembelajaran yang masih bersifat konvensional dengan menggunakan buku, papan tulis dan alat peraga lainnya sebagai alat belajar siswa, media pembelajaran ini masih kurang menarik bagi siswa terutama dalam pelajaran pengenalan huruf-huruf abjad. Sekarang ini anakanak lebih cenderung suka belajar menggunakan media yang berhungan dengan teknologi terutama anak-anak usia dini, dikarenakan lebih cepat menyerap pelajaran dari gambar-gambar menarik yang mendidik dan sesuai dengan usianya. Peneliti membuat media pembelajaran interaktif berbasis Flash untuk lebih mudah mengenalkan huruf kepada siswa pendidikan anak usia dini pada Kelompok Belajar Tarbiyatul Ummah. Media pembelajaran ini dimulai dari proses analisis kebutuhan yang akan digunakan dalam pembuatan media pembelajaran interaktif dan membuat konsep atau perancangan sesuai dengan hasil analisis.
\end{abstract}

Kata kunci : Media pembelajaran, Media interaktif, Teknologi, Adobe Flash

\begin{abstract}
The purpose of this study is to facilitate teachers in delivering material to students and increase student understanding of the material presented and as a medium to increase interest in learning and enjoyment in the learning process. Learning media have an important role in the teaching and learning process, but the reality in the world of education is that learning media is often ignored for reasons of limited time to make teaching preparations and it is difficult to find the right media. In the Tarbiyatul Ummah Tanak Kaken Learning Group using learning media that are still conventional in nature by using books, blackboards and other teaching aids as student learning tools, this learning media is still less attractive to students, especially in introducing letters of the alphabet. Nowadays children are more likely to love learning to use media that is related to technology, especially early childhood, because it is faster to absorb lessons from interesting images that are educational and ageappropriate. Researchers create interactive Flash-based learning media to more easily introduce letters to early childhood education students in the Ummah Tarbiyatul Learning Group. This learning media starts from the needs analysis process that will be used in making interactive learning media and making concepts or designs in accordance with the results of the analysis.
\end{abstract}

Keywords: Learning media, interactive media, technology, Adobe Flash

\section{Pendahuluan}

Kemajuan teknologi mengalami perkembangan

yang sangat cepat dan terbukti berperan dalam

berbagai aktivitas. Keberadaan teknologi dapat mendukung kinerja peningkatan efisiensi, efektivitas, dan produktivitas bagi berbagai instansi, baik instansi pemerintah negeri, swasta maupun perorangan atau individual, khususnya 
dalam dunia pendidikan yang menyesuaikan dengan teknologi yang berkembang saat ini, salah satunya menggunakan media pembelajaran berbasis multimedia. Pendidikan mempunyai peran penting dalam perkembangan manusia seutuhnya. Pendidikan sangat perlu untuk dikembangkan dari berbagai ilmu pengetahuan, karena pendidikan yang berkualitas dapat meningkatkan kecerdasan suatu bangsa. Oleh karena itu media pembelajaran sangat penting digunakan pada suatu proses penyampaian yang dilakukan oleh seseorang kepada orang lain atau antara pendidik maupun kepada peserta didik. Awalnya guru masih menggunakan metode ceramah, alat peraga maupun papan tulis untuk bisa menyampaikan materi pengenalan huruf abjad kepada peserta didik. PAUD Tarbiyatul Ummah adalah salah satu sekolah pendidikan tingkat pertama yang ada di Dusun Tongka Desa Tanak Kaken Kecamatan Sakra Barat. PAUD Tarbiyatul Ummah Tanak Kaken menggunakan media pembelajaran yang masih manual menggunakan media buku, papan tulis dan alat peraga sebagai alat belajar, media pembelajaraan ini masih kurang menarik bagi siswa terutama dalam pelajaran mengenal huruf-huruf abjad, dikarenakan materi yang disampaikan menggunakan tulisan di papan tulis dan alat peraga diam dan tidak ada audio atau suara. Maka dari itu perlu perubahan dalam metode pembelajarannya menggunakan metode pembelajaran yang baru dan lebih menarik, salah satunya dengan memanfaatkan teknologi multimedia sebagai media pembelajaran interaktif, sehingga dengan adanya metode pembelajaran yang baru ini bisa meningkatkan minat belajar siswa.

\section{Tinjauan Pustaka}

\subsection{Penelitian Terkait}

Ada beberapa penelitian yang sudah dilakukan sebelumnya yang terkait dengan penelitian ini antara lain :

Menurut Wirasasmita, R. H., \& Putra, Yupi K. Dalam penelitiannya berjudul Pengembangan Media Pembelajaran Video Tutorial Interaktif Menggunakan Aplikasi Camtasia Studio Dan Macromedia Flash, menyatakan bahwa Media pembelajaran berbasis video $C D$ tutorial interaktif ini dapat menjadi suplemen bagi mahasiswa walaupun sifatnya hanya pilihan tapi dapat dimanfaatkan juga untuk menambah pengetahuan, wawasan khususnya tentang matakuliah bahasa pemrograman visual materi bahasa pemrograman delphi serta memudahkan proses belajar mengajar serta meningkatkan kualitas pembelajaran dan prestasi belajar mahasiswa[1]. Sedangkan menurut Sudianto, A., \& Samsu, L. M. Bahwasanya media pembelajaran interaktif lebih efektif dari metode pembelajaran ceramah. Karena metode ceramah hanya membuat siswa lebih menjadi pasif dan apabila menerapkan media pembelajaran interaktif lebih memancing respon siswa terhadap suatu pelajaran[2]. Dalam penelitian 
yang dilakukan oleh Bahtiar $H$. dkk, menyimpulkan bahwa dengan adanya digitalisasi Karya TGKH. Muhammad Zainuddin Abdul Madjid berbasis mobile sebagai media pembelajaran interaktif untuk pelestarian peninggalan pendiri Nahdlatul Wathan menjadi salah satu soluai akan membantu murid-murid beliau yang notabennya tidak memiliki kitab tersebut dan terhalang dengan jarak dan waktu. Pengerjaan dimulai dengan pengetikan isi kitab yang dilanjutkan dengan implementasi aplikasi, dan pada akhirnya aplikasi bisa dimanfaatkan lebih lanjut[3]. Menurut Zaini, B. \& Saputri, M. P. dalam penelitiannya menyatakan bahwa produk media yang dibuat berisikan gambar, grafik, teks, dan musik latar yang bisa membuat menarik dalam penyampaian media pembelajaran. Serta tentang pengenalan huruf, suku kata, soal latihan dan informasi. Produk media pembelajaran yang dibuat berguna untuk membantu siswa-siswi untuk mempelajari materi pengenalan huruf dan suku kata[4]. Sedangkan menurut Nofikasari, I. dkk menyatakan bahwa Konsep aplikasi pembelajaran interaktif, atraktif dan menarik dengan tiga bahasa akan memberikan beberapa keuntungan seperti media pembelajaran interaktif dengan tiga bahasa yaitu bahasa Indonesia, Bahasa Inggris dan Bahasa Arab, evaluasi siswa, dan meningkatkan pemahaman siswa[5].

\subsection{Landasan Teori}

1. Definisi Multimedia

Definisi multimedia beragam tergantung pada lingkup aplikasi serta perkembangan teknologi multimedia itu sendiri. Multimedia tidak hanya memiliki makna antara teks dan grafik sederhana saja, tetapi juga dilengkapi dengan suara, animasi, video, dan interaksi. Sambil mendengarkan penjelasan dapat melihat gambar, animasi maupun membaca penjelasan dalam bentuk teks. Multimedia mengkombinasi teks, seni, suara, gambar, animasi, dan video yang disampaikan dengan komputer dan dapat disampaikan secara interaktif.[6] Berbagai sumber tentang pengertian multimedia yang menyebutkan bahwa multimedia adalah kumpulan dari berbagai elemen media seperti teks, grafik, gambar, video, animasi, audio dan interaktif yang tersaji ke dalam satu media dan memiliki fungsi saling mendukung antara satu dengan yang lainnya sehingga dapat memberikan pengaruh dan rangsangan terhadap tujuan pembelajaran.[7]

\section{Definisi Media}

Kata media berasal dari bahasa latin medium yang secara harafiah berarti tengah, perantara atau pengantar. Secara khusus pengertian media dalam proses belajar mengajar lebih cenderung diartikan sebagai alat tulis grafis, fotografis, atau elektronik untuk menangkap, memproses, dan menyusun kembali informasi visual atau verbal[8]. Criticos (dalam Daryanto, 
2011: 4) "Media merupakan salah satu komponen komunikasi, yaitu sebagai pembawa pesan dari komunikator menuju komunikan".

\section{Media Pembelajaran}

Media pembelajaran adalah segala sesuatu seperti: alat, benda, lingkungan, dan lain-lain yang dapat digunakan untuk menyampaikan informasi atau pesan khususnya bahan pelajaran. Sehingga dengan menggunakan media pembelajaran dalam proses belajar mengajar dapat mempermudah pendidik dalam menyampaikan bahan pelajaran kepada peserta didik. Selain itu menggunakan media dalam proses belajar mengajar juga dapat merangsang perhatian dan minat siswa untuk memperhatikan dan memahami materi pelajaran yang disampaikan oleh pendidik sehingga dapat tercapainya tujuan belajar. Tujuan penggunaan media belajar dalam proses belajar mengajar bukan sekedar untuk melengkapi proses belajar mengajar dan untuk menarik perhatian peserta didik saja, akan tetapi penggunaan media dalam proses belajar mengajar itu bertujuan untuk memfasilitasi dan mempermudah proses belajar mengajar sehingga dapat meningkatkan kualitas belajar mengajar dan tercapainya tujuan belajar[9]. Menurut [10], mengemukakan manfaat media pengajaran dalam proses belajar siswa yaitu : Pengajaran akan lebih menarik perhatian siswa sehingga dapat menumbuhkan motivasi belajar. Bahan pengajaran akan lebih jelas maknanya sehingga dapat lebih dipahami oleh siswa dan memungkinkannya menguasai dan mencapai tujuan pengajaran.

\section{Media Pembelajaran Interaktif}

Media pembelajaran adalah alat atau sarana yang digunakan untuk melaksanakan proses belajar mengajar. Baik berupa alat elektronik atau alat peraga, media pembelajaran interaktif adalah proses belajar mengajar yang menggunakan media atau sarana yang bisa saling berkomunikasi atau saling merespon[11]. Komputer memiliki program-program aplikasi praktis yang dapat dimanfaatkan dan dikembangkan untuk pencapaian tujuan pendidikan. Beberapa orientasi penggunaan komputer dalam dunia pendidikan adalah bagaimana komputer dapat membantu orang untuk belajar, untuk mengajar, dan membantu orang dalam mengelola pendidikan secara umum. Begitu juga dalam pengembangan bahan-bahan atau materi pembelajaran, sebagai alternatif sumber belajar, komputer digunakan untuk mentransfer materi- materi kepada peserta didik atau dalam konteks ini biasa disebut dengan bahan pembelajaran berbasis computer [3].

\section{Multimedia Interaktif}

Multimedia interaktif adalah suatu multimedia yang dilengkapi dengan alat pengontrol yang dapat dioperasikan oleh pengguna, sehingga pengguna dapat memilihapa yang dikehendaki untuk proses selanjutnya. Contoh multimedia 
interaktif adalah pembelajaran interaktif, aplikasi game[12]. Bentuk-bentuk dalam pemanfaatan model dalam media pembelajaran interaktif berbasis komputer maupun android dalam media pembelajaran terdapat berupa drill, tutorial, simulation, dan games. Pada dasarnya salah satu tujuan pembelajaran dengan multimedia interaktif adalah sedapat mungkin menggantikan dan atau melengkapi serta mendukung unsurunsur seperti tujuan, materi, metode, dan alat penilaian yang ada dalam proses belajar mengajar dalam sistem pendidikan konvensional yang biasa kita lakukan[13].

\section{Adobe Flash}

Adobe flash adalah sebuah tools/software pengolah dan pembuat animasi 2 dimensi berbasis gambar vector. Adobe flash juga dapat digunakan untuk keperluan pembangunan situs web yang interaktif dan dinamis juga pembuatan aplikasi berbasis web, desktop ataupun mobile. Keunggulan yang dimiliki oleh Flash ini adalah ia mampu diberikan sedikit code pemrograman baik yang berjalan sendiri untuk mengatur animasi yang ada di dalamnya atau digunakan untuk berkomunikasi dengan program lain seperti HTML, PHP, dan Database dengan pendekatan $\mathrm{XML}$, dapat dikolaborasikan dengan web, karena mempunyai keunggulan antara lain kecil dalam ukuran file outputnya. Bahasa pemrograman yang digunakan di Adobe Flash adalah Action Script. Action Script 2.0 (ditujukan untuk penggunaan platform desktop) dan Action Script
3.0 (ditujukan untuk penggunaan platform mobile)[14].

\section{Metode}

\subsection{Desain Penelitian}

Pada penelitian ini terdapat beberapa tahapan sebagai berikut :

1. Tahap pengumpulan informasi dan data mengenai media pembelajaran yang digunakan.

2. Tahap Analisis

Tahapan analisis ini bertujuan untuk memperoleh media dan metode pembelajaran apa saja yang digunakan para pengajar untuk menyampaikan materi kepada siswa..

3. Tahap Pembuatan Sistem

Pada tahapan pembuatan sistem media pembelajaran interaktif untuk mengenalkan huruf abjad kepada siswa, dengan pembuatan sistem ini juga diharapkan dapat digunakan oleh siswa dalam meningkatkan minat belajar.

4. Experimen dan Pengujian

Berdasarkan hasil dari sistem media pembelajaran interaktif yang telah dibuat, akan dilakukan uji coba untuk melihat apakah sistem yang dibuat dapat berjalan sesuai dengan yang diinginkan.

5. Evaluasi

Setelah dilakukan pengujian dan experimen terhadap hasil media pembelajaran interaktif yang telah dibuat, maka bisa dilihat 
perbedaan dari hasil yang dilakukan sebelumnya, apakah dengan pembuatan media pembelajaran interaktif berbasis flash ini dapat membantu meningkatkan minat belajar siswa.

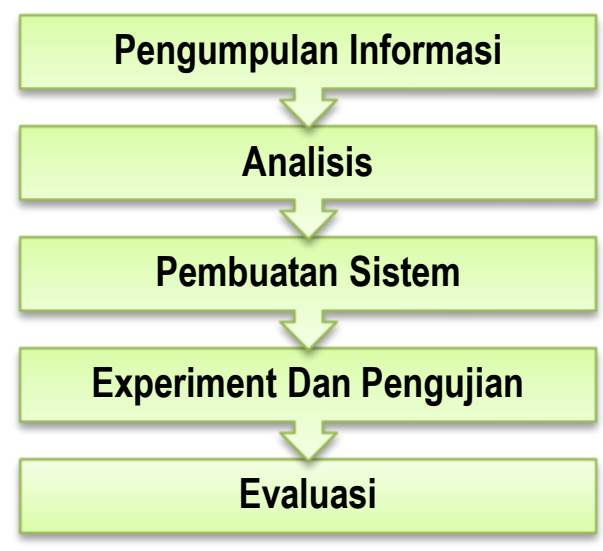

Gambar 1. Tahapan Penelitian

\subsection{Prosedur Penelitian}

Adapun prosedur peneltian yang dilakukan oleh peneliti mulai dengan menganalisis permasalahan yang terdapat pada proses belajar mengajar di PAUD Tarbiyatul Ummah dan metode pembelajaran apa saja yang digunakan para pengajar untuk menyampaikan materi kepada siswa. Serta media pembelajaran yang diperlukan dalam menyampaikan materi kepada siswa.

\subsection{Sumber Data}

\section{Data Primer}

Sumber data yang digunakan oleh peneliti adalah hasil dari wawancara dan observasi terhadap proses belajar mengajar anak-anak di PAUD Tarbiyatul Ummah dan melihat metode pembelajaran apa saja yang digunakan para pengajar untuk menyampaikan materi kepada siswa.

\section{Data Sekunder}

Sedangkan dalam pengumpulan data sekunder menggunakan buku, jurnal, publikasi dan lainlain serta data yang sebelumnya pernah dibuat oleh seseorang baik di terbitkan atau tidak.

\subsection{Instrumen Penelitian}

Menurut[15] "Instrumen penelitian adalah suatu alat yang digunakan untuk mengukur nilai variabel yang diteliti dengan tujuan menghasilkan data kuantitatif yang akurat, maka setiap instrumen harus mempunyai skala". Instrumen penelitian yang digunakan dalam penelitian ini adalah dengan mengamati langsung pada obyek penelitian serta dengan cara wawancara.

\subsection{Teknik Pengumpulan Data}

Teknik pengumpulan data dalam penelitian ini menggunakan metode observasi, wawancara dan studi literatur.

\section{Oberservasi}

Teknik observasi yakni teknik pengumpulan data dimana peneliti mengadakan pengamatan langsung terhadap objek yang diteliti. Disini peneliti terjun langsung ke lapangan untuk melihat proses belajar mengajar anak-anak di PAUD Tarbiyatul Ummah dan melihat metode pembelajaran apa saja yang digunakan para pengajar untuk menyampaikan materi kepada siswa. Tujuan observasi ini untuk membantu peneliti dalam mengambil keputusan, sehingga 
peneliti tau tindakan apa yang akan dilakukan selanjutnya.

\section{Wawancara}

Teknik ini merupakan teknik yang dilakukan peneliti secara langsung dilokasi dengan teknik tanya jawab langsung dengan para pengajar yang ada di PAUD Tarbiyatul Ummah. Tujuan wawancara ini untuk memperoleh informasi yang akurat

\section{Studi Literatur}

Studi Pustaka merupakan teknik pengumpulan data dan informasi melalui buku-buku referensi. melalui internet dan sumber-sumber lainnya yang sesuai dengan obyek yang diteliti.

\subsection{Teknik Analisis Data}

\section{Analisis Permasalahan}

Melakukan analisis terhadap permasalahan yang dihadapi terkait dengan proses belajar mengajar anak-anak di PAUD Tarbiyatul Ummah dan melihat metode pembelajaran apa saja yang digunakan para pengajar untuk menyampaikan materi kepada siswa, serta memberikan solusi terhadap masalah yang ditemukan.

\section{Analisis Kebutuhan}

Peneliti menganalisis kebutuhan media pembelajaran yang diperlukan dalam menyampaikan materi kepada siswa.

\subsection{Lokasi Penelitian}

Lokasi dalam penelitian ini dilakukan di Pendidikan Anak Usia Dini (PAUD) Tarbiyatul Ummah Tanak Kaken Kecamatan Sakra Barat.

\section{Hasil dan Pembahasan}

Media pembelajaran interaktif pengenalan huruf abjad ini diterapkan pada Pendidikan Anak Usia Dini (PAUD) Tarbiyatul Ummah Tanak Kaken Kecamatan Sakra Barat sebagai media belajar mengajar yang lebih menarik dan menyenangkan. Dengan adanya media pembelajaran interaktif ini, dapat menarik minat belajar dan menambah motivasi anak selama belajar sehingga didapatkan hasil pembelajaran yang maksimal. Selain itu, dapat membantu guru dalam menyampaikan materi kepada siswa dengan mudah melalui media pembelajaran interaktif ini. Adapun hasil dari uji coba aplikasi media pembelajaran interaktif pengenalan huruf abjad ini adalah sebagai berikut :

1. Menu Intro

Tampilan menu intro merupakan tampilan pertama saat program dijalankan.

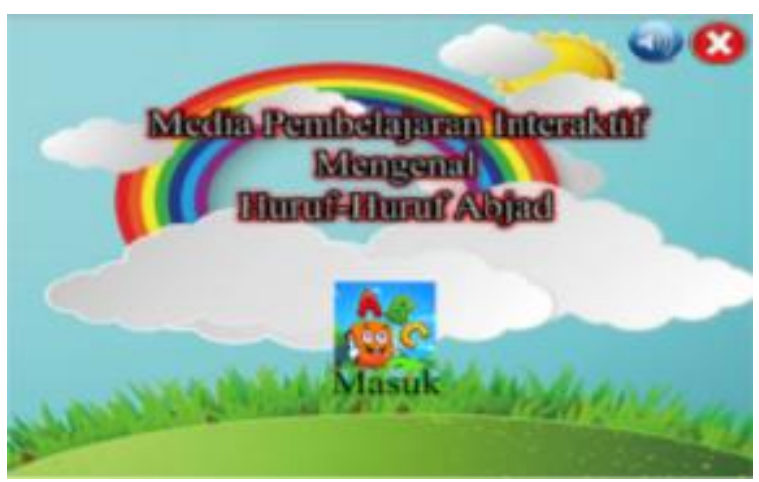

Gambar 2. Menu Intro

\section{Menu Utama}

Menu utama merupakan menu pokok dalam program aplikasi media pembelajaran interaktif mengenal huruf-huruf abjad pada siswa Pendidikan Anak Usia Dini (PAUD), dalam menu 
utama ini terdapat empat pilihan yakni doa belajar, materi, vide, dan quiz.

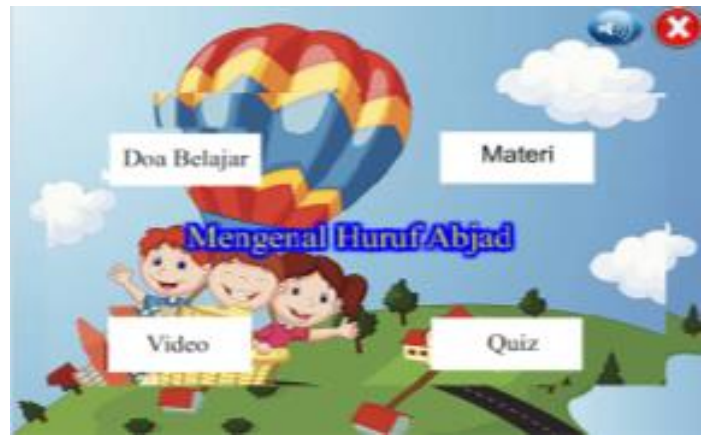

Gambar 3. Menu Utama

\section{Menu Doa Belajar}

Didalam menu doa belajar ada dua tombol pilihan yaitu doa sebelum belajar dan doa sesudah belajar.

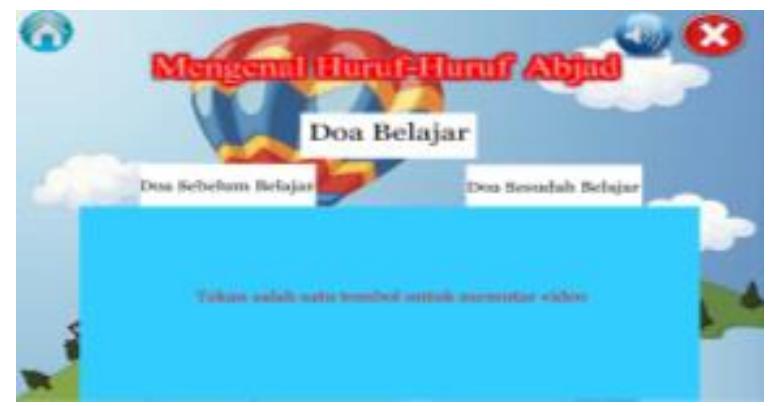

Gambar 4. Menu Do'a Belajar

\section{Menu Materi}

Didalam menu materi terdapat dua sub menu yaitu huruf kapital dan huruf kecil.

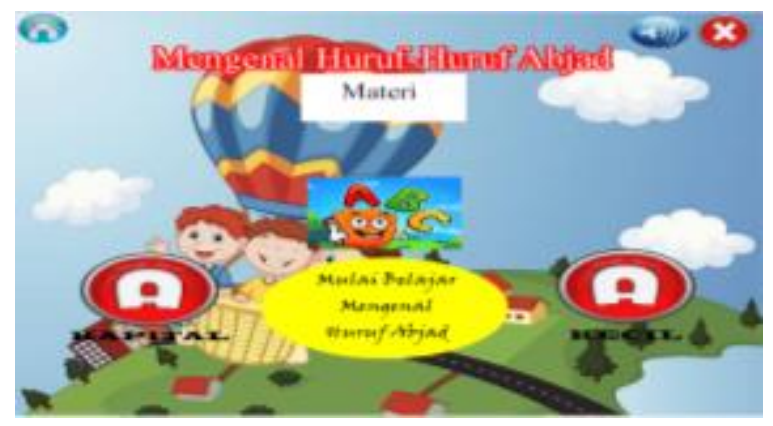

Gambar 5. Menu Materi

\section{Menu Video}

Dalam menu video memiliki lima tombol pilihan yaitu video1, video2, video3, video4, video5. Untuk memutar salahsatu dari videonya dengan cara menekan tombol video.

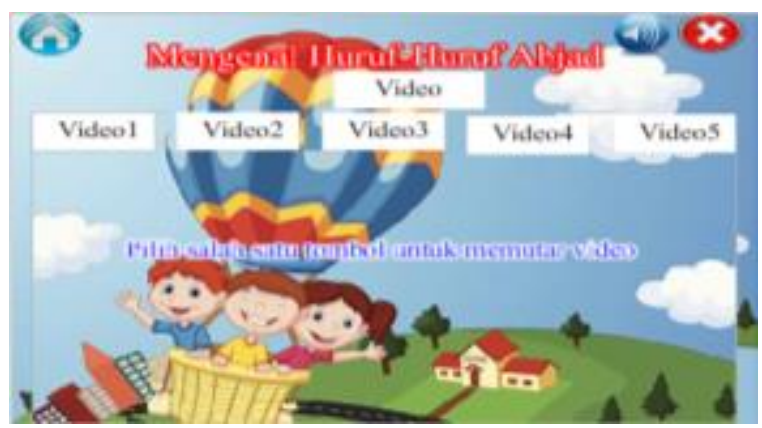

Gambar 6. Menu Video

6. Menu Quiz

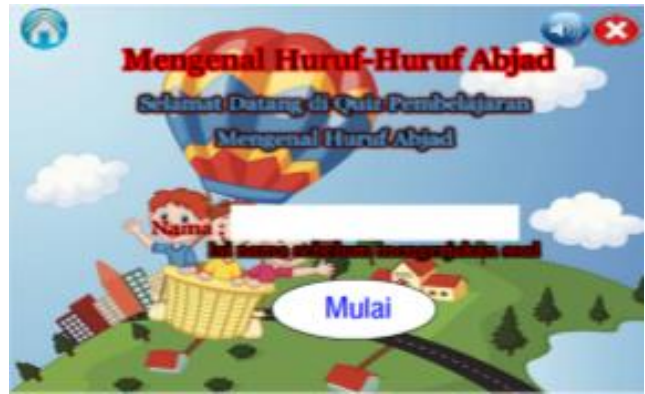

Gambar 7. Menu Quiz

Gambar di atas merupakan tampilan setelah tombol quiz pada menu utama di tekan, untuk memulai kuis tekan tombol mulai yang ada pada halaman quiz. Untuk tampilan soal seperti gambar di bawah ini :

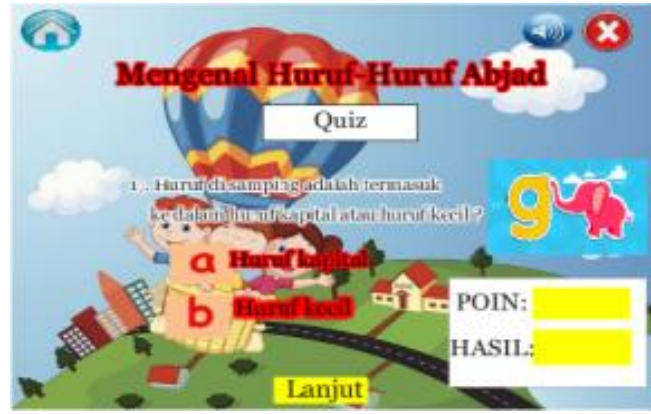

Gambar 8. Tampilan Soal 


\section{Kesimpulan}

Pembuatan media pembelajaran interaktif berbasis adobe flash cs6 pada media pembelajaran mengenal huruf-huruf abjad untuk Pendidikan Anak Usia Dini (PAUD) ditunjukkan agar dapat mempermudah guru dan siswa dalam proses belajar mengajar. Dengan adanya media pembelajaran interaktif ini bisa memotivasi siswa untuk belajar lebih giat dan meningkatkan minat belajar dan kesenangan dalam proses belajar siswa. Dikarenakan media interaktif ini menggabungkan suara, gambar dan video yang dikemas agar dapat menarik minat belajar siswa dan memberikan motivasi baru dalam proses belajar mengajar.

\section{Daftar Pustaka}

[1] Y. K. Wirasasmita, Rasyid Hardi; Putra, "PENGEMBANGAN MEDIA PEMBELAJARAN VIDEO TUTORIAL INTERAKTIF MENGGUNAKAN APLIKASI CAMTASIA STUDIO DAN MACROMEDIA FLASH," EDUMATIC J. Pendidik. Inform., vol. 1, no. 2, pp. 35-43, 2017.

[2] L. M. S. Aris Sudianto, "Penerapan Media Pembelajaran Interaktif Pelajaran Bahasa Indonesia Berbasis Android Untuk Kelas Vii Madrasah Tsanawiyah Nahdlatul Wathan Ketangga Sebagai Upaya Untuk Peningkatkan Minat Belajar Siswa," Infotek J. Inform. dan Teknol., vol. 2, no. 2, pp. 5360, 2019.

[3] B. H. Hariman Bahtiar, Muhamad Wasil, "Digitalisasi Karya TGKH. Muhammad Zainuddin Abdul Madjid berbasis mobile sebagai media pembelajaran interaktif untuk pelestarian peninggalan pendiri Nahdlatul Wathan," Infotek J. Inform. dan Teknol., vol. 2, no. 1, pp. 1-7, 2019.

[4] B. Zaini and M. P. Saputri, "Pengembangan
Media Pembelajaran Interaktif Contextual Teaching and Learning (CTL) Untuk Siswa Pendidikan Anak Usia Dini (PAUD) di PAUD SAHABAT," PINTER J. Pendidik. Tek. Inform. dan Komput., vol. 1, no. 2, pp. 90 100, 2017, doi: 10.21009/pinter.1.2.2.

[5] I. Nofikasari et al., INDUKSI TEKNOLOGI MEDIA PEMBELAJARAN BERBASIS MULTIMEDIA INTERAKTIF PADA PAUD AISIYAH AL-, no. September. 2019.

[6] I. Diah, S. Nita, D. T. Informatika, F. Teknik, and U. P. Madiun, "Media Pembelajaran Berbasis Multimedia Interaktif untuk Meningkatkan Pemahaman Konsep Mahasiswa," vol. 1, no. 2, pp. 68-75, 2018.

[7] G. Mussardo, "Definisi Multimedia dan Unsur Multimedia," Stat. F. Theor, vol. 53, no. 9, pp. 1689-1699, 2019, doi: 10.1017/CBO9781107415324.004.

[8] Arsyad, Media Pembelajaran. Jakarta: PT. Raja Grafindo Persada, 2011.

[9] E. F. Fahyuni, "Inovasi Model Pembelajaran," p. 16, 2016.

[10] and A. R. Sudjana, Nana, "Media Pengajaran (Penggunaan \& Pembuatannya)."' Sinar Baru Aglesindo, Bandung, 2011.

[11] A. and Munir, "Media Pembelajaran Interaktif," vol. 13, no. 128, p. 234, 2011.

[12] Daryanto, Media Pembelajaran. Bandung: PT $S$ a $r$ a $n$ a Tutorial Nurani Sejahtera, 2011.

[13] S. H. and M. lalu Samsu, "Penerapan Media Pembelajaran Interaktif Pelajaran Bahasa Indonesia Berbasis Android Untuk Kelas Vii Madrasah Tsanawiyah Nahdlatul Wathan Ketangga Sebagai Upaya Untuk Peningkatkan Minat Belajar Siswa," FLEPS 2019 - IEEE Int. Conf. Flex. Printable Sensors Syst. Proc., vol. 6, no. 1, pp. 1-46, 2019, doi: 10.1016/j.surfcoat.2019.125084.

[14] I. Mustaqim and E. Prianto, "Modul Pelatihan Media Pembelajaran Adobe Flash," Fak. Tek. Univ. Negeri Yogyakarta, no. April, pp. 1-45, 2015.

[15] Sugiyono, Metodelogi Penelitian Kuantitatif, Kualitatif Dan R\&D. Bandung: CV. ALFABETA, 2013. 